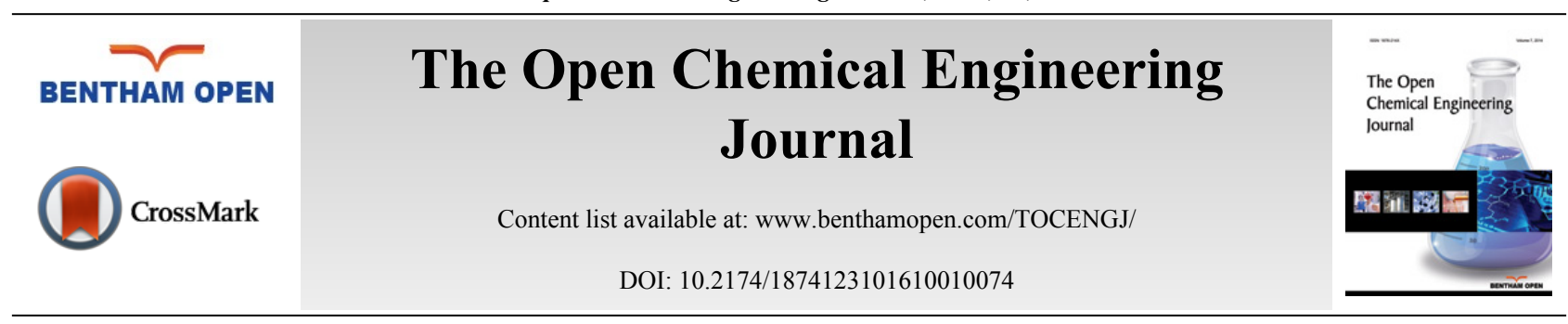

\title{
Mass and Heat Transfer at Different Heat Exchange Surfaces and Their Suitability for Use in Thermal Desalination Plants
}

\author{
T. Schwarzer ${ }^{1, *}$ and H.J. Bart ${ }^{2}$ \\ ${ }^{1}$ Forschungszentrum Jülich, Wilhelm-Johnen-Str., 52428 Jülich, Germany \\ ${ }^{2}$ Chair of Separation Science and Technology, University of Kaiserslautern, D-67663 Kaiserslautern, Germany
}

Received: October 20, 2015

Revised: March 15, 2016

Accepted: March 16, 2016

\begin{abstract}
A new concept for small scale multi-stage distillation (MSD) desalination plants is presented allowing an installation in remote rural areal due to low maintenance, operating and investment costs. It is based on extensive studies on heat and mass transfer using 6 different condensation / heat transfer surfaces or material combinations. Basically all 6 condensation surfaces except glass are of a sheet metal or an expanded metal (to the evaporation side) in combination to an acid- and heat-resistant foil (on the salt water side). The basic experiments were performed in a "lab scale" unit to determine their thermodynamic and structural characteristics and user-friendliness. After validation in a prototype novel oxidic condensation surfaces (AF) and material combinations are in actual use in the new MSD systems, following the requirements, including a good wetting and condensation behavior and a good heat transfer.
\end{abstract}

Keywords: Distillate, Drinking water, Dripping back losses, Heat and mass-transfer, Multi-stage, Scaling, Solar thermal desalination.

\section{INTRODUCTION}

Given the shortage of drinking water $[1,2]$ numerous methods for large-scale seawater and brackish water desalination processes have been developed [3,4]. These processes are state of the art and find a world-wide distribution. Because of high capital and operating costs and often non-existent infrastructure necessary for the largescale desalination plants, in many rural regions of the world, especially in developing and emerging countries, these large plants are not suitable. There is a need for desalination systems, which have low construction and maintenance costs during operation. Many solar powered desalination systems and models have been developed around the world and presented in various publications [5 - 7].

At the Solar Institute Jülich (SIJ) of the University of Applied Sciences, Aachen, in cooperation with the engineering office for Energy and Environmental Technology (IBEU), a self-powered solar desalination system for decentralized applications in arid regions was developed [8 - 10]. For the first time, novel heat transfer material combinations of metal sheets or expanded metal and heat-resistant plastic films (50 microns thickness) are used. They show besides good heat transfer properties also a good condensation behavior due to their hydrophilic properties. In addition, easy cleaning of the condensation resp. heat transfer surface is required for continuous operation of the plant. Similar studies for heat transport in polymeric falling-film heat exchangers were carried out at the Chair of Separations Science and Technology at the TU Kaiserslautern, especially in respect to their scaling propensity [11, 12]. This new heat exchanger concept is an attractive low cost alternative to conventional multi-effect distillation (MED) plants [13 $15]$.

This paper describes a new apparatus concept and quantifies the performances in mass and heat transfer of the MSD

\footnotetext{
* Address correspondence to this author at the Projektträger Jülich, Erneuerbare Energien, Photovoltaik, Solarthermie (EEN1), Forschungszentrum Jülich GmbH, 52425 Jülich, Germany; Tel: 02461 61-9157; Fax: 02461 61- 2840; Email: t.schwarzer@fz-juelich.de
} 
system. Furthermore, the choice of materials and optimization is discussed as well as special advantages due to antiscaling properties. This publication is of special interest for the design and operation of novel small scale desalination plants.

\section{MATERIALS, METHODS, AND EXPERIMENTAL RESULTS}

\subsection{Solar desalination system (SDS)}

The developed MDS (Fig. 1) represents a new type of solar thermal desalination plants with heat recovery. The MSD with several stacked floors (stages) utilizes at any stack the heat of condensation. Due to the thermal energy transfer at the bottom tank the salt water is heated in the lowest level to about 95 to $100^{\circ} \mathrm{C}$ and brought to evaporation. The vapors are ascending from the top of a liquid loaded stack (stage) and moist air is condensed on the underside of an overlying stack (stage). The energy released by the condensation enthalpy of vaporization is released at the overlying stage and heats the salt water therein. The achieved heat recovery reduces the specific heat demand per liter of distillate.

The entire plant is energy self-sufficient and self-regulating, no electrical power is needed to operate the system. A pump is not required, because the transfer of heat from the solar collectors in the desalination plant is via natural convection. Instead of using solar energy, the desalination system may also be operated with thermal energy from any other energy source.

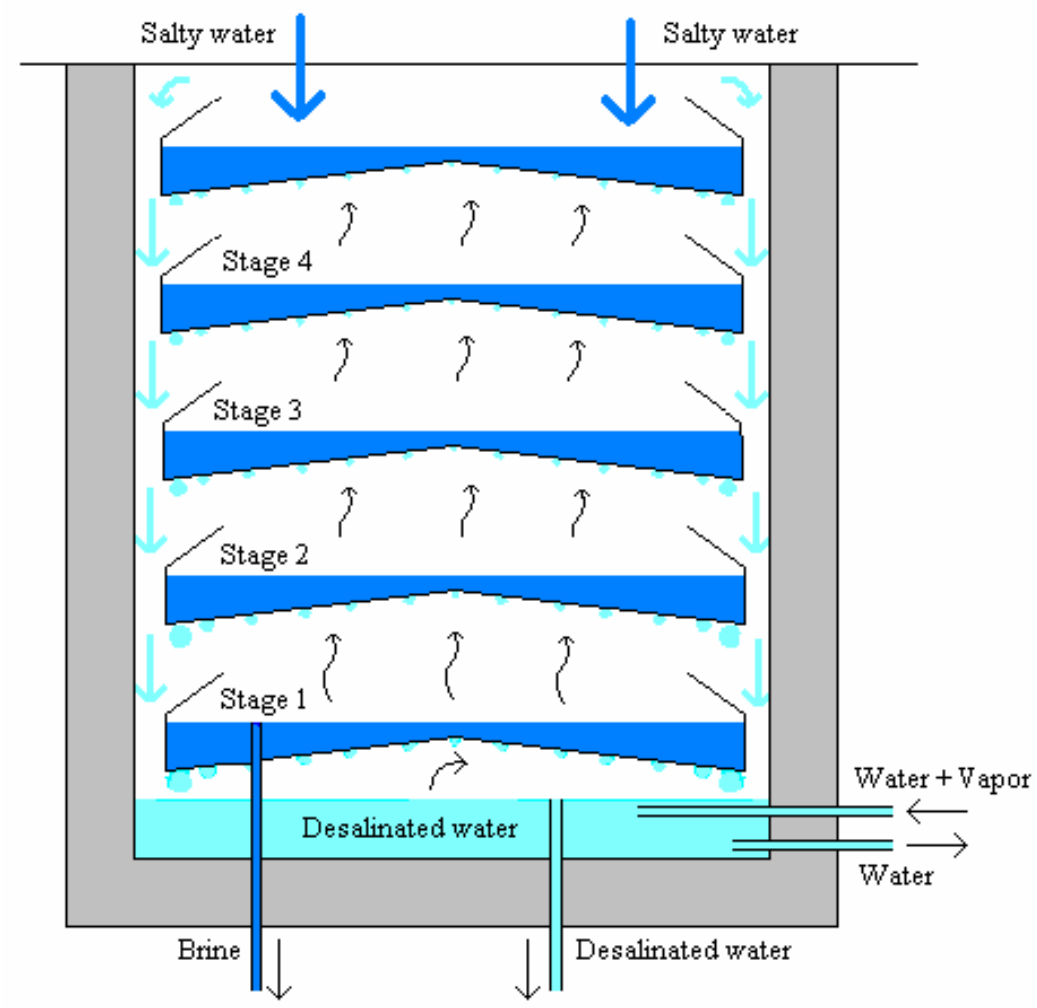

Fig. (1). Schematic view of the MSD system.

When designing the MSD systems, it should be noted that the water mass in the condensation stages is small to ensure dimensional stability. In addition, too much water in any stage results to a certain thermal inert behavior and to lower operating temperatures and consequently to a lower distillate production. In order to have optimal conditions the angle of the condensation surfaces are therefore low to ensure a constant water flow and at the same time good wetting characteristics (good condensation), to have low back drip losses of condensate. In addition to that a low corrosion tendency in respect to hot salty water, easy cleaning and low material and construction costs, are limiting the materiel selection of the condensation stages. 


\subsection{Lab Scale Test Rig}

For accurate analysis of the mass and heat flow the test rig is consisting of a reservoir and a condensation stage, where the condensing surfaces can be easily exchanged (Fig. 2). The size of the exchangeable condensation surfaces is uniform $50 \mathrm{~cm} \times 50 \mathrm{~cm}$. Heat input is provided with an electric heater and a cooling circuit is integrated with a water thermostat. Using a temperature control between the water storage (tank bottom, $\mathrm{T}_{S t o}$ ) and the top level, $\mathrm{T}_{S t, l}$, a certain temperature difference for a given storage temperature $\mathrm{T}_{S t o}$ can be set. The heater simulates the thermal energy introduced at real outdoor testing conditions. The inclination of the condensing surface can be varied in this experimental setup as required. Due to the inclination of the condensing surface, the condensate flows into the collecting gutter and is measured. Sliding angles of $5^{\circ}$ and $10^{\circ}$ were chosen. To determine the maximum rate corresponding to the condensation and the condensation rate, a sliding angle of $20^{\circ}$ was chosen. In the bottom of the tank, a magnetic stirrer is attached, which provides a uniform temperature distribution in the tank.

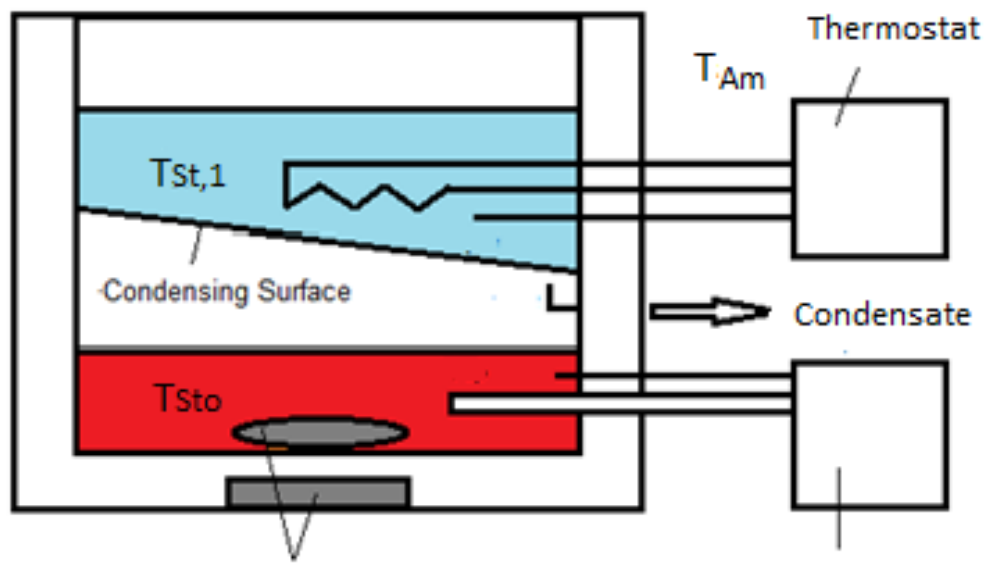

Magnetic Stirrer

Heater

Fig. (2). Setup of the lab scale plant.

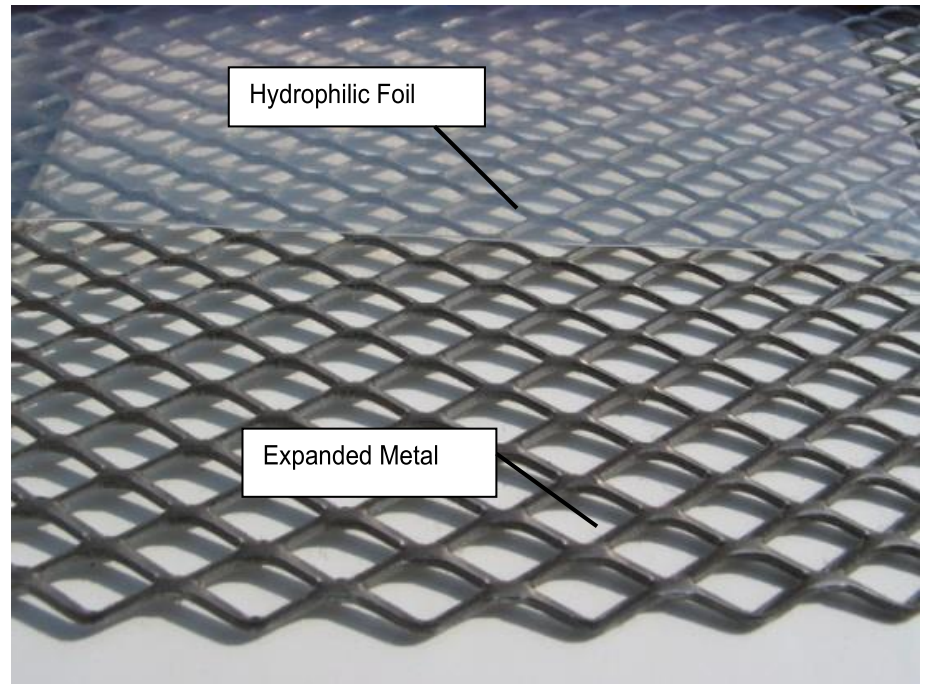

Fig. (3). Condensation surface with expanded metal and hydrophilic foil beneath.

\subsection{Condensing Surfaces}

Basically all 6 condensation surfaces except glass (GF) are of a sheet metal or an expanded metal (at the evaporation side) in combination to an acid and heat resistant foil (on the salt water side). The foil takes over the sealing function of the condensation stage and prevents inter alia the corrosion from salt water on the metallic surfaces. In addition, the foil facilitates cleaning of the condensation stages (no solid deposits). Fig. (3) shows a condensation surface consisting of an expanded metal structure and a hydrophilic foil. The condensate passes between the expanded metal and the foil to the 
gutter. In addition to untreated stainless steel surfaces (UB), stainless steel surfaces with nano-coatings (NF), metal sheets with an oxidic surface (AF) on the condensation side, expanded metal with a temperature-resistant foil (UF) and a hydrophilic foil (BF) were investigated.

\subsection{Theory}

The energy balance for the test rig is:

$$
\begin{gathered}
m_{S t o} c_{p} \frac{d T}{d t}=\dot{Q}_{e l}-k_{1} A_{S t, 1}\left(T_{S t o}-T_{S t, 1}\right)-k_{2} A_{W}\left(T_{S t o}-T_{A m}\right) \\
k_{1}=\frac{1}{\frac{1}{\alpha_{1}}+\frac{S_{1}}{\lambda_{1}}+\frac{1}{\alpha_{2}}}
\end{gathered}
$$

The following parameters have an influence on the performance of the energy flow balance: The water mass $m_{\text {Sto }}$ in the storage, the electrical power $\dot{Q}_{e l}$ of the heating coil or another heat source, the condensation surface $A_{S t, I}$ of the stage, the wall and floor surface $A_{W}$, the heat transfer coefficient $\mathrm{k}_{1}$ and the heat transfer coefficient of the outer surface $\mathrm{k}_{2}$. The second right side term represents the heat flow from the reservoir to the overlying level and the third right side term in equation (1) is represents the heat losses through the side walls. Since the walls and the floor of the test rig are insulated with $6 \mathrm{~cm}$ thick polyurethane, the heat losses through the walls and the floor are negligibly small. After adjusting various storage and stage temperatures, which are based on prior performed measured stage temperatures in a prototype system, the measurements are carried out under constant conditions. From these measurements one can determine the heat transfer coefficient $\mathrm{k}_{1}$, the theoretically possible condensation rate $\dot{m}_{t h}$ and the back drip losses depending on the temperature, the sliding angle of the condensing surface and the nature of the condensing surface.

Under steady state conditions the following is valid:

$$
m_{S t o} c_{p} \frac{d T}{d t}=0
$$

and when substituting in Equation 1, $\mathrm{k}_{1}$ can be estimated as:

$$
k_{1}=\frac{\dot{Q}_{e l}-\frac{\lambda_{W} A_{W}\left(T_{S t o}-T_{A m}\right)}{S_{W}}}{A_{S t, 1}\left(T_{S t o}-T_{S t, 1}\right)}
$$

The results of the measurements [16] show that it is convenient to calculate the theoretical condensation rates, the measured rates of condensation and condensation efficiency as a function of a mean temperature, Tm, in the system, which is defined as:

$$
T_{m}=\frac{T_{S t o}+T_{S t, 1}}{2}
$$

Using the experimental results, an expression for $\mathrm{k}_{1}$ can be written as:

$$
k_{1}\left(T_{m)}=5,0014 \frac{W}{m^{2} K} * e^{0,0398 \frac{T_{m}}{{ }^{\circ} \mathrm{C}}}\right.
$$

Fig. (4) shows the values determined by measurements as a function of the mean temperature Tm. The coefficient of determination for this correlation is $98.6 \%$. The heat flow $\dot{Q}_{S t o-S t, 1}$ from the reservoir into the overlying level to the condensing surface can be represented using the temperature differences $T_{S t o}-T_{S t, 1}$ between the storage and the first stage.

The determination of the $\mathrm{k}_{1}$-values is carried out for 6 different condensation stages. It is shown that due to the good thermal conductivity of the condensation surfaces $\left(1-1.5 \mathrm{~mm}\right.$ thickness) the heat flux can be described by a single $\mathrm{k}_{1}$ value sufficiently accurate. These determined - values are strongly temperature dependent. The temperature dependence 
arises particularly from changes of the value on the condensation side through variation of the vapor temperature. This overall value gives the heat transport by evaporation, convection and radiation. The knowledge of these values is sufficient for the heat transport.

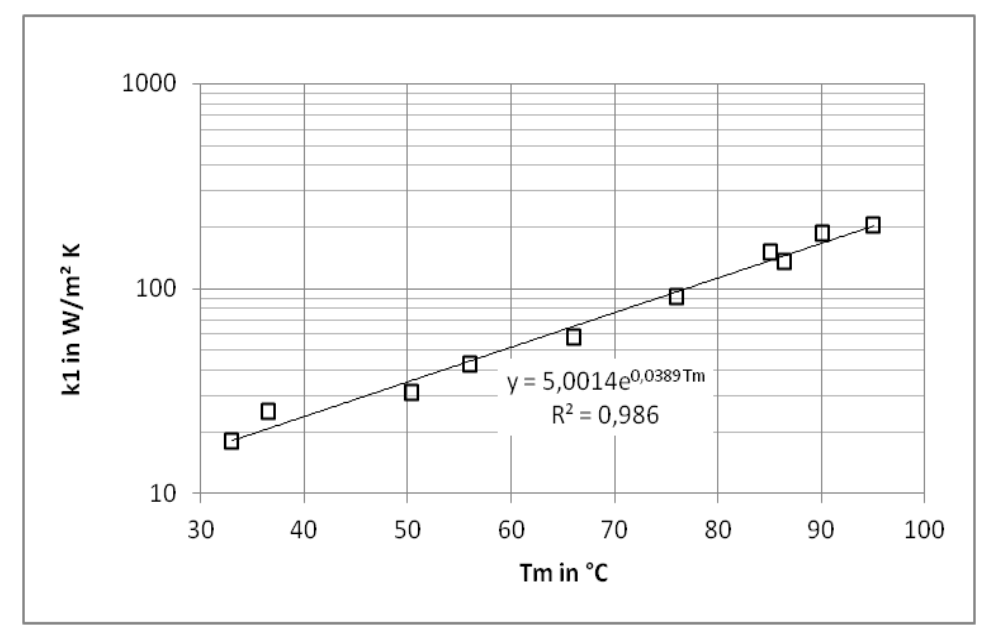

Fig. (4). Dependence of the $\mathrm{k}_{1 \text { - }}$ values of the mean temperature $T_{m}$.

\subsubsection{Maximal Specific Condensation Rate $\dot{m}_{t h, s p}\left(T_{m}\right)$}

To assess the suitability of condensing surface, the knowledge of the "maximal" specific condensation rate is important. The determination of the theoretical specific rate of condensation is carried out as described above but with large condensation drain angles $\left(>20^{\circ}\right)$, which exclude rear drip losses. Due to no return drip losses relating to drain angles $>20^{\circ}$, the maximum condensate rate corresponds to the theoretical condensation rate. For this reason, the maximum measured condensation rate is set equal to the theoretical condensation rate.

Fig. (5) shows the measured maximal specific or theoretical condensation rate $\dot{m}_{t h, s p}\left(T_{m}\right)$ in $\mathrm{g} /\left(\mathrm{m}^{2} \mathrm{hK}\right)$ as a function of the mean temperature between the storage and the first stage. Using the experimental data, an expression for $\dot{m}_{t h, s p}\left(T_{m}\right)$ can be written as,

$$
\dot{m}_{t h, s p}\left(T_{m}\right)=3,835 \frac{g}{m^{2} h K} * e^{0,0471 \frac{T_{m}}{{ }^{\circ} C}}
$$

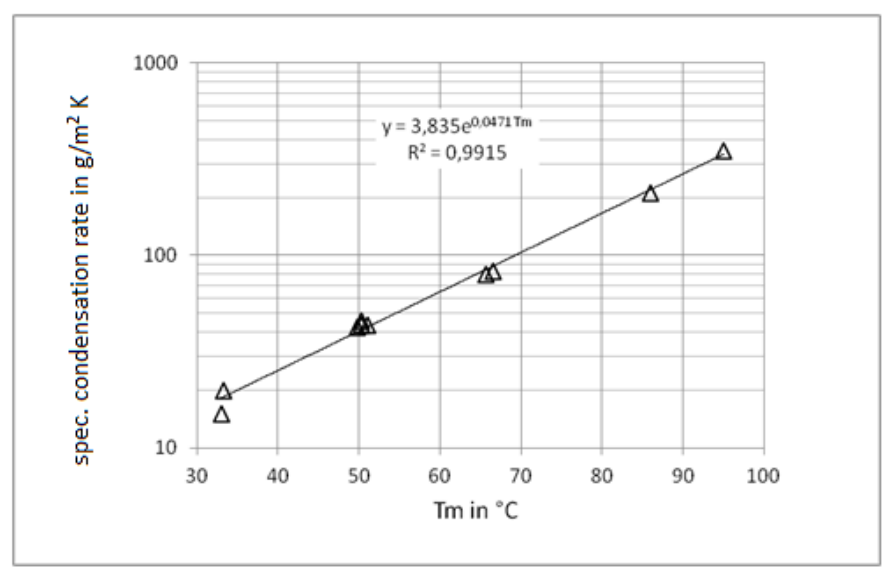

Fig. (5). Measured specific condensation rate as a function of Tm.

\subsubsection{Drip Losses}

The wetting behavior of surfaces at condensation is determined by interaction of cohesion and adhesion forces. The balance between the weight force of the drop and the adhesive forces is determined by the material of the condensing surface, the surface texture and the influence of temperature. Water, due to its strong dipole, exhibits strong adhesion 
forces especially with oxidic surfaces. Depending on the evaporator and condenser temperature, there are also different condensation mechanisms. At low temperatures (range of low rates of condensation), water with is high surface tension reinforces drop wise condensation. Under these conditions (low process temperature) higher reverse drip losses result. At a higher temperature range (range of high rates of condensation) film condensation and only small rear drip losses occur.

The assessment of the actual collected condensation rate for different temperature ranges and for different tilt angle is necessary for assessing the suitability of a condensing surface. An important parameter is the condensation yield $\eta_{\text {con }}\left(T_{\mathrm{m}}\right)$. The condensation yield indicates how much of the theoretical specific amount of condensation $\dot{m}_{t h, s p}\left(T_{m}\right)$ is collected as condensate $\dot{m}_{s p, C o n}\left(T_{m}\right)$.

$$
\eta_{\text {Con }}\left(T_{m}\right)=\frac{\dot{m}_{s p, C o n}\left(T_{m}\right)}{\dot{m}_{t h, s p}\left(T_{m}\right)}
$$

From the determined theoretical condensation rate and the measured condensation rates, the rear drip losses / rear drip rates for each condensing surface can be estimated remotely accurate. The back drop rate $\dot{R}\left(T_{m}\right)$ is then:

$$
\dot{R}\left(T_{m}\right)=\dot{m}_{t h, s p}\left(T_{m}\right)-\dot{m}_{s p, C o n}\left(T_{m}\right)
$$

\subsubsection{Material Selection}

A comparison of the different surfaces with respect to the specific measured condensation rate (see Fig. 6) explains the choice of the final condensation surfaces for a usage in the MSD system. For large runoff angle $\left(10^{\circ}\right)$, the oxidic surfaces, the hydrophilic film expanded metal combination, the nano-coated stainless steel and the glass surfaces are suitable. Upon closer examination, the oxide metal surfaces hydrophilic films combinations and glass show in the lower temperature range better condensation behavior compared to stainless steel. At $10^{\circ}$ sliding angle, NF-10 shows a good condensation behavior, even in the low temperature range. However, it would need further investigation in terms of durability of the nano-coating and their suitability for drinking water. Fig. (7) shows clearly the behavior of appropriate condensation surfaces even at a low sliding angle of $5^{\circ}$. The metal oxide surfaces have also a high specific rate of condensation for this sliding angle, followed by glass and the expanded metal hydrophilic film combination.

Fig. (8) shows a comparison of the rates of condensation of an AF and UB condensing surface as a function of the sliding angle. The oxide condensation surface with a sliding angle greater than $3^{\circ}$ has a condensate yield of $90 \%$. For smaller angles, the flow rate of condensation will fall down to $0 \%$. The condensate will not flow on the condensing surface to the gutter, but fall back to the lower level. Using the condensation surface of stainless steel, rear drip losses are significantly higher due to the low adhesion. Even with sliding angle angles of $10^{\circ}$ to $15^{\circ}$, only about $60 \%$ of the condensate is collected. The mean temperature $\mathrm{T}_{\mathrm{m}}$ was $50^{\circ} \mathrm{C}$.

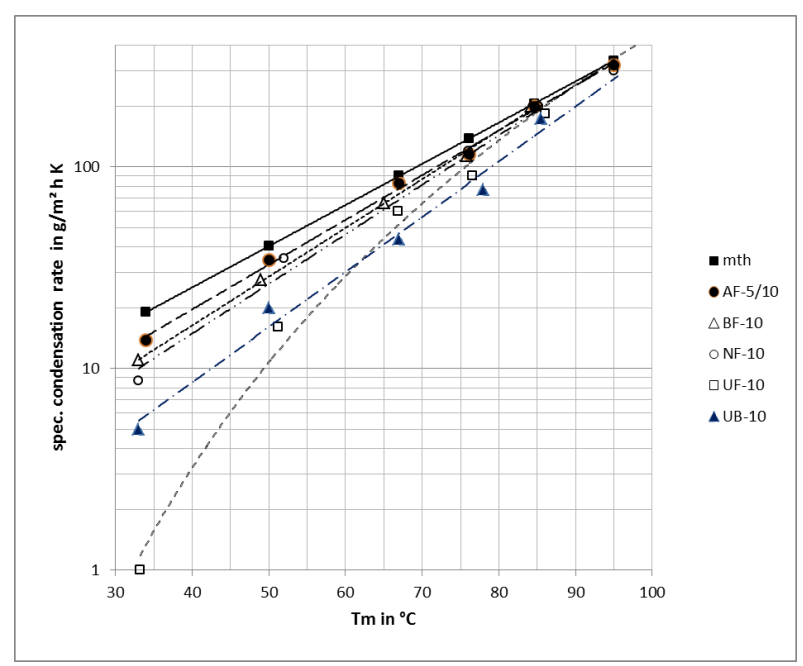

Fig. (6). Specific condensation rates at a sliding angle of $10^{\circ}$. 


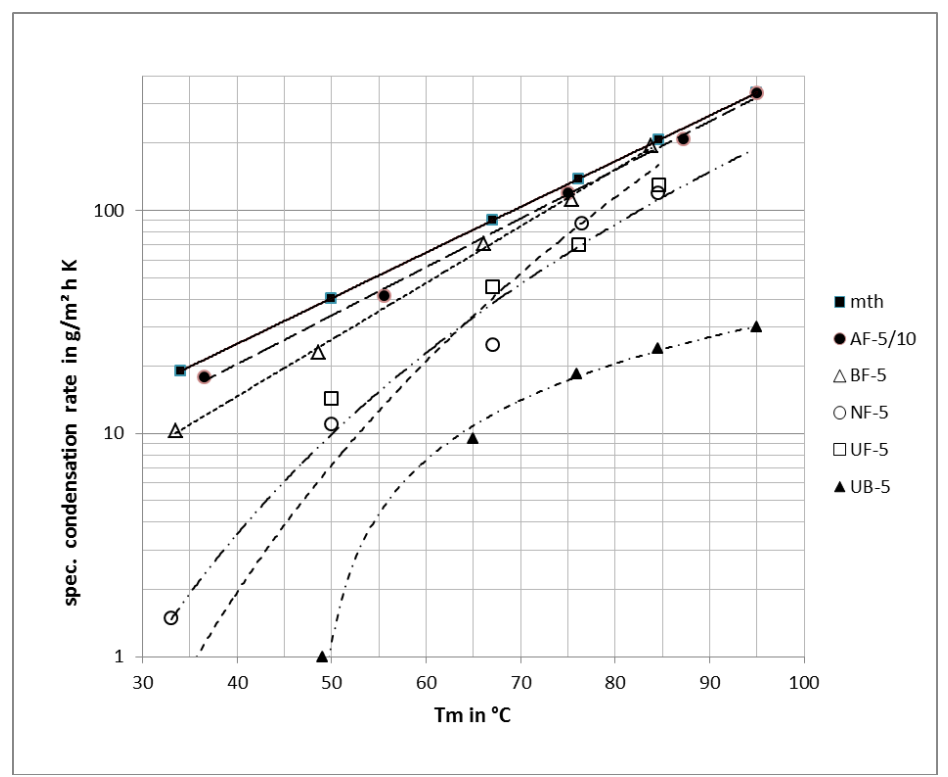

Fig. (7). Specific condensation rates at a sliding angle of $5^{\circ}$.

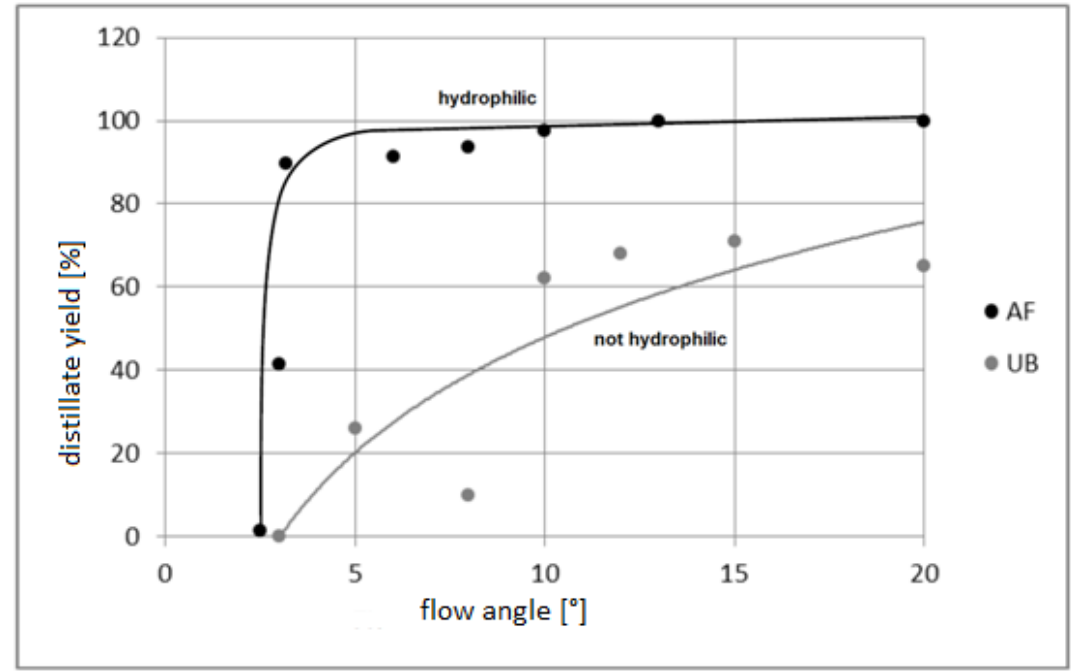

Fig. (8). Distillate yield for an oxidic (AF) and a stainless steel (UB) condensing surface with $\mathrm{Tm}=50^{\circ} \mathrm{C}$.

\subsubsection{Total Specific Rate of Condensation}

A significant advantage of the representation of the specific measured condensation rate as a function of the mean temperature $T_{m}$ is that the relationship can be expressed functionally. Table. 1 shows the functions of the specific condensation rates of the examined condensation surfaces for $5^{\circ}$ and $10^{\circ}$. Equation 10 gives the total specific condensation rate for the various baffles estimate on an n-stage system (column 3 in Table 1). As reference temperatures the upper temperature $\mathrm{T}_{\mathrm{m} \text {, up }}=97^{\circ} \mathrm{C}$ and the lower temperature $\mathrm{T}_{\mathrm{m} \text {, low }}=35^{\circ} \mathrm{C}$ is selected. Column 4 shows the calculated GOR values (Gain Output Ratio) for steady-state operation at a heat flux $\dot{Q}_{\text {in }}$ of $0.8 \mathrm{~kW}$ and a condensing surface of $\mathrm{A}_{\mathrm{St}}=1 \mathrm{~m}^{2}$ (s. equation 11). The condensation rate $\dot{m}_{C o n}$ is not depending on the temperature profile in the system, but only on the temperature difference $T_{m, ~ u p}-T_{m, ~ l o w}$.

In the first line of Table $\mathbf{1}$, the maximum rate of condensation $\dot{m}_{\mathrm{th}, \mathrm{sp}}$ is listed for a condensation surface with a sliding angle of $20^{\circ}$. For a temperature range between $\mathrm{Tm}, \mathrm{up}=97^{\circ} \mathrm{C}$ and $\mathrm{Tm}, \mathrm{low}=35^{\circ} \mathrm{C}$ results a condensation rate of $\dot{m}_{\text {Con }}=7427 \mathrm{~g} /\left(\mathrm{m}^{2} \mathrm{~h}\right)$ with a GOR value of 5.94. When reducing the sliding angle from $10^{\circ}$ to $5^{\circ}$, the return drip losses increase particularly strongly using UB, and the GOR value of 3.84 decreases to less than unity. The obtained values from the test rig were validated by experimental results with a MSD system with 7 stages. Using oxide condensation surfaces (AF) a GOR value $>5$ is reached (see Table 1). The achieved GOR value for the desalination system with 7 desalination stages is about 5 to 5.5 . 


$$
\dot{m}_{\text {Con }}=\int_{T_{m u}}^{T_{m o}} \dot{m}_{s p}\left(T_{m}\right) d T_{m}
$$

For steady-state operation, the GOR-value is calculated as follows:

$$
G O R=\frac{\dot{m}_{C o n} * r}{\dot{Q}_{\text {in }}}
$$

In transient operation, such as is present in solar-powered systems, the GOR value is:

$$
G O R=\frac{m_{\text {Con }} * r}{Q_{\text {in }}}
$$

$Q_{i n}$ stands for the introduced energy into the desalination system (energy provided from the collector field), $m_{\text {Con }}$ for the total amount of distillate produced in the system (in all stages) and $r$ for the specific enthalpy of vaporization.

\begin{tabular}{|c|c|c|c|}
\hline Condensation surface & $\dot{m}_{s p}(T m)$ & $\dot{m}_{\text {Con }}$ & GOR \\
\hline$\dot{m}_{\text {th }, \mathrm{sp}}\left(20^{\circ}\right)$ & $3,835 \frac{g}{m^{2} h K} * e^{0,0471 * T_{m} /{ }^{\circ} \mathrm{C}}$ & $7427 \frac{g}{m^{2} h}$ & 5,94 \\
\hline $\mathrm{UB}-5^{\circ}$ & $\frac{0,6582 \mathrm{~g}}{m^{2} h K} * T m-31,902 \mathrm{~g} / \mathrm{m}^{2} \mathrm{hK}$ & $783 \frac{g}{m^{2} h}$ & 0,62 \\
\hline $\mathrm{UB}-10^{\circ}$ & $\frac{0,6864 g}{m^{2} h K} * \exp ^{0,063 * T m /{ }^{\circ} \mathrm{C}}$ & $4813 \frac{g}{m^{2} h}$ & 3,84 \\
\hline $\mathrm{NF}-5^{\circ}$ & $\frac{1 E-07 * T m^{4,602} g}{m^{2} h K}$ & $2399 \frac{g}{m^{2} h}$ & 1,90 \\
\hline $\mathrm{NF}-10^{\circ}$ & $\frac{1,542 g}{m^{2} h K} * \exp ^{0,0567 * T m /{ }^{\circ} \mathrm{C}}$ & $6456 \frac{g}{m^{2} h}$ & 5,16 \\
\hline $\mathrm{UF}-5^{\circ}$ & $\frac{7 E-10 * T m^{5,8784} g}{m^{2} h K}$ & $4710 \frac{g}{m^{2} h}$ & 3,68 \\
\hline $\mathrm{UF}-10^{\circ}$ & $\frac{7 E-09 * T m^{5,4001} g}{m^{2} h K}$ & $5670 \frac{g}{m^{2} h}$ & 4,52 \\
\hline $\mathrm{BF}-5^{\circ}$ & $\frac{1,414 g}{m^{2} h K} * \exp ^{0,0585 * T m /{ }^{\circ} \mathrm{C}}$ & $6581 \frac{g}{m^{2} h}$ & 5,18 \\
\hline $\mathrm{BF}-10^{\circ}$ & $\frac{1,758 g}{m^{2} h K} * \exp ^{0,0557 * T m /{ }^{\circ} \mathrm{C}}$ & $6787 \frac{g}{m^{2} h}$ & 5,37 \\
\hline $\mathrm{AF}-5 / 10^{\circ}$ & $\frac{3,095 g}{m^{2} h K} * \exp ^{0,049 * T m /{ }^{\circ} \mathrm{C}}$ & $6972 \frac{g}{m^{2} h}$ & 5,59 \\
\hline GF-5/10 & $\frac{2,4792 g}{m^{2} h K} * \exp ^{0,0516 * T m /{ }^{\circ} \mathrm{C}}$ & $6875 \frac{g}{m^{2} h}$ & 5,28 \\
\hline
\end{tabular}

Table 1. Specific rates of condensation of the investigated condensation surfaces and the GOR values for an 8-stages plant with drain angle of $5^{\circ}$ and $10^{\circ}$.

\subsection{Results With Oxidic Condensations Surfaces At Lab Scale}

For further evaluation of the overall efficiency a multi-stage MSD-plant (lab scale system) with 8 oxide condensations surfaces was built with a condensation surface per stage of $1 \mathrm{~m}^{2}$. The heat was supplied by an electric 
heater of $1.0 \mathrm{~kW}$. The measurements allow a comparison of a real desalination (see chapter 3 ) system based on the values of lab scale test rig.

Fig. (9) shows the temperature profile for 24 hour batch operation inside an 8-stage MSD system using AF-5 condensation surfaces. The electric heater started operating in the morning at 2:45 a.m., being noticed by a rapid rise in temperature in the lower stages. At 15:30 p.m. the maximum temperature of $98^{\circ} \mathrm{C}$ is reached in the electric heater automatically gives a warning signal. For the entire test period the electrical consumption and the amount of distillate of the individual stages are hourly been collected so that sufficient data for the thermodynamic characterization of the system are available.

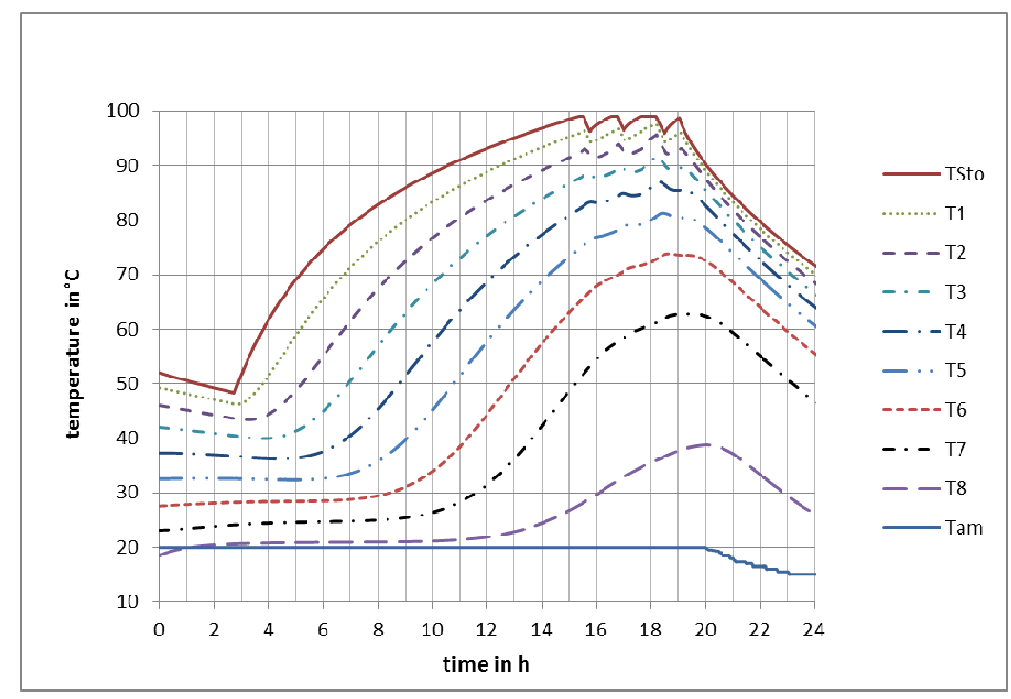

Fig. (9). Measured temperature profile in the MSD plant (laboratory system).

Fig. (10) shows that when approaching a steady state, a displacement of the condensation rate is carried out from the lower to the upper levels (stages). The stage production falls within the lower levels despite rising temperature, while the upper levels have a production increase with increasing time. This is due to a decreasing of the temperature difference between the stages in the lower stages at a high temperature level, while in the upper stages the temperature rises further. At 18:45 p.m. the stationary state of the system is achieved. While maintaining at this operating state, no further increase in temperature will occur.

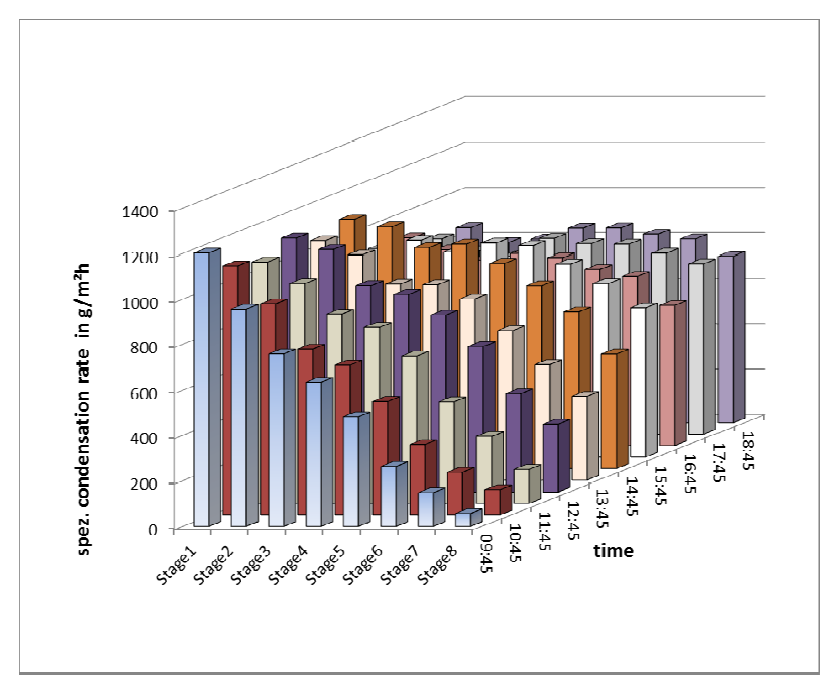

Fig. (10). Specific condensation rates at different temporal heating phases. 
Fig. (11) shows the specific condensation rates of 8 stages in the stationary state (stationary state condition also apparent in Table 1). The specific rates of condensation for each stage are between $0,86 \mathrm{~kg} / \mathrm{m}^{2} \mathrm{~h}$ and $0,73 \mathrm{~kg} / \mathrm{m}^{2} \mathrm{~h}$. The overall level of production results to $6,5 \mathrm{~kg} / \mathrm{m}^{2} \mathrm{~h}$. The GOR value is about 5,5 and the average stage efficiency is ca. $81 \%$. For the transient operation (24 h operation) results a GOR value of 3,9.

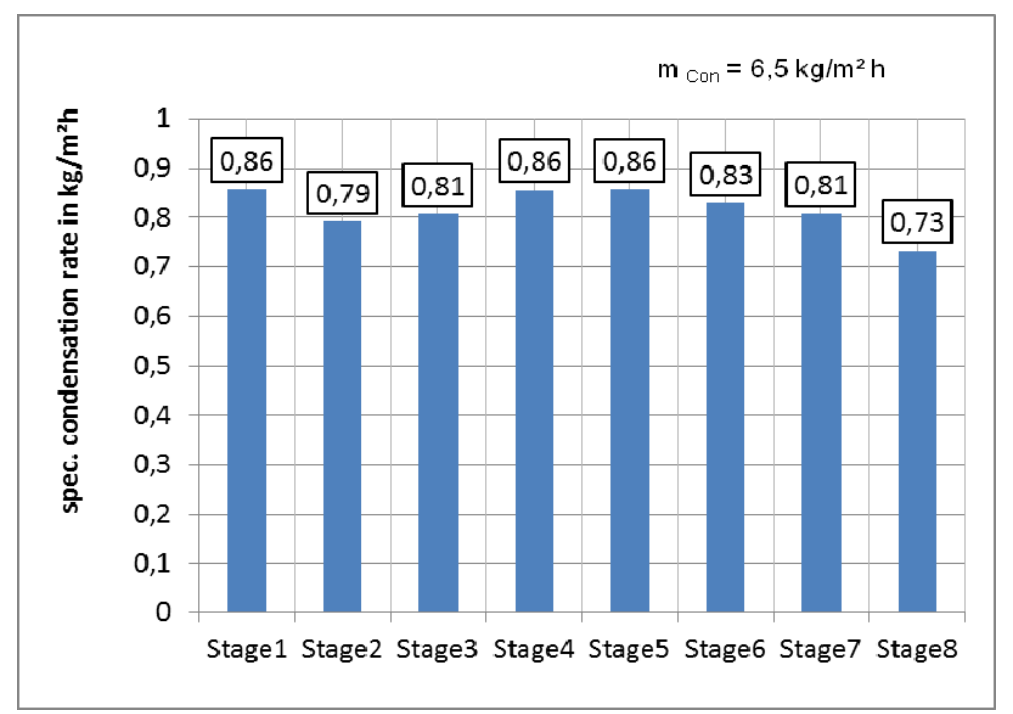

Fig. (11). Specific condensation rate in quasi-stationary operating state.

Fig. (12) shows the measured daily production of the individual stages of the 8-stage system compared with the values from the calculation with equation 10 and 12. The entire condensate production is approximately 74 liters, the calculated value 73 liters. The condensation ratio falls with the increasing number of stages. The condensation rate per day for the first stage is approximately $16,5 \mathrm{~kg}$, the lower stages only provide approximately $4,5 \mathrm{~kg}$.

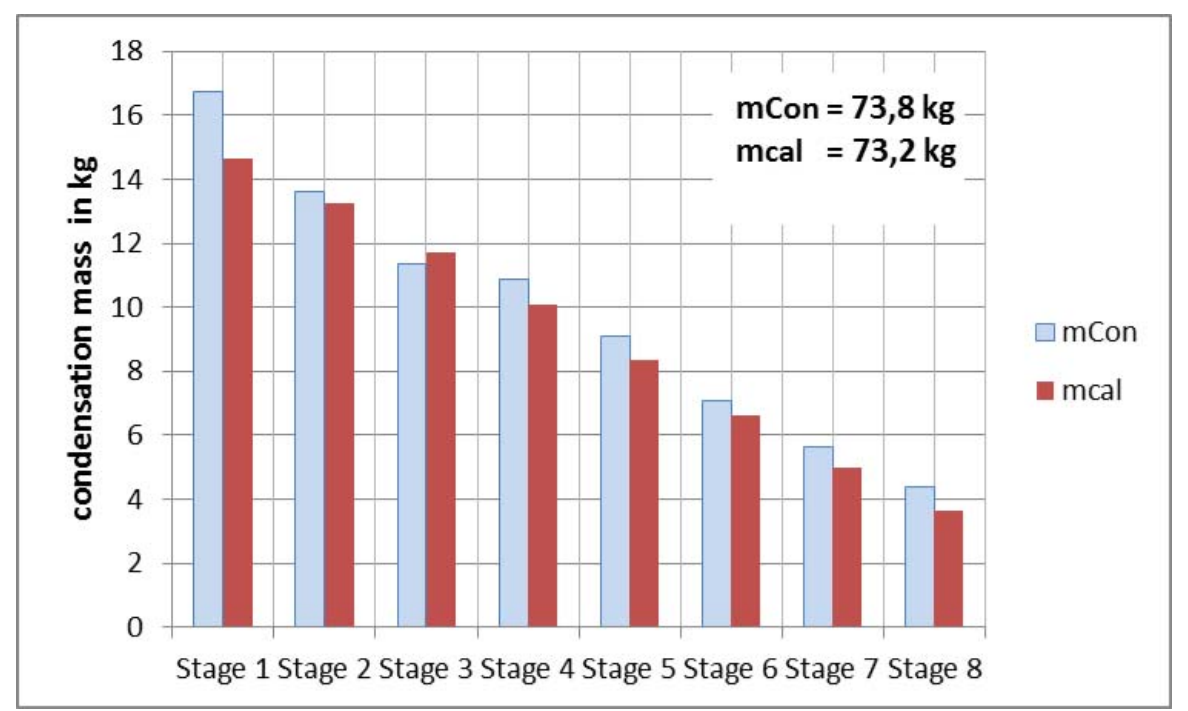

Fig. (12). Comparison of the stage production for the experimental period $(24 \mathrm{~h})$.

The results show a good agreement between the measured and the calculated values and confirm the simple and practical application of mathematical and physical relationships shown above.

\section{RESULTS WITH PROTOTYPE}

In the first distillation plants, when applying the new MSD principle, rather costly stainless steel condensation stages have been used. In addition to the high material and manufacturing costs increased scaling was decisive in the search for cheap materials with low scaling affinity. The experience from the simple test rig and lab scale experiments led to several changes in the system design of the desalination plant and finally to a user-friendly and marketable 
prototype. There currently are 6 plants with this design to obtain drinking water from saline groundwater in Namibia for 4 years in operation. The operating experience with these systems confirms the advantage of the new evaporator / condensation surface. These systems impress due to its high condensate production, its relatively simple structure and its easy cleaning process, by separating the metal surface and salt water through a thin self-cleaning plastic film. The deposits can be easily removed by blowing or spraying with a water jet. This enables a fast and effective cleaning process outdoors. In addition, the film prevents any kind of corrosion on the evaporator / condensation surface. Due to the multiple heat recovery of the distillate depending on the type of system, 12 to 17 liter per day was obtained per $\mathrm{m}^{2}$ collector area. Fig. (13) shows the installed plants in Namibia [10, 17] with a daily production of about 500 liters of potable water by good radiation from saline groundwater. The potable water is always available for the village community at a water supply station, shown in Fig. (14).

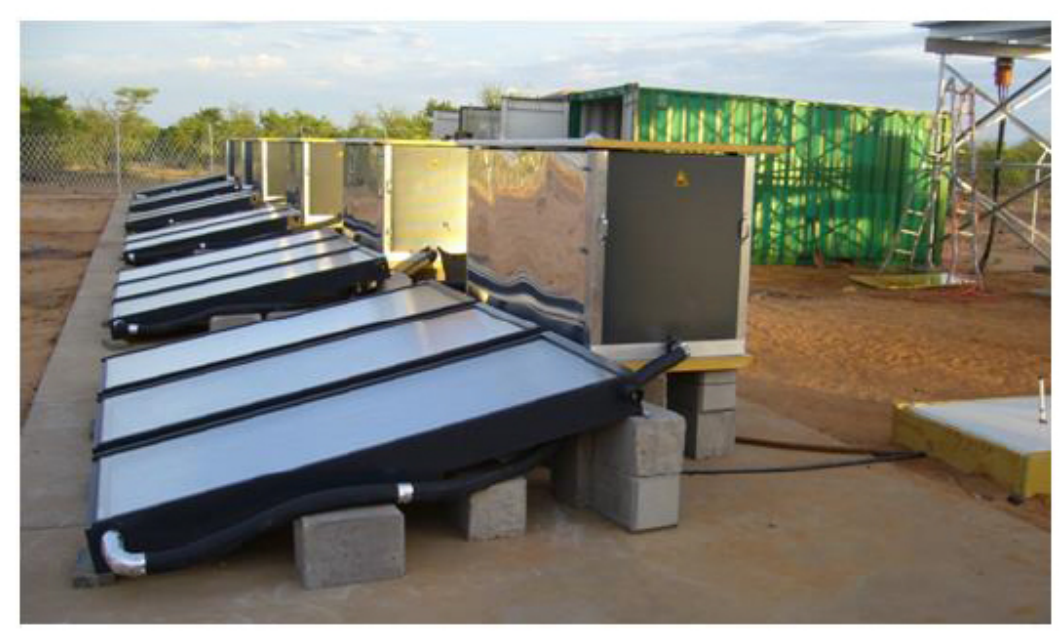

Fig. (13). MSD-desalination systems in Namibia.

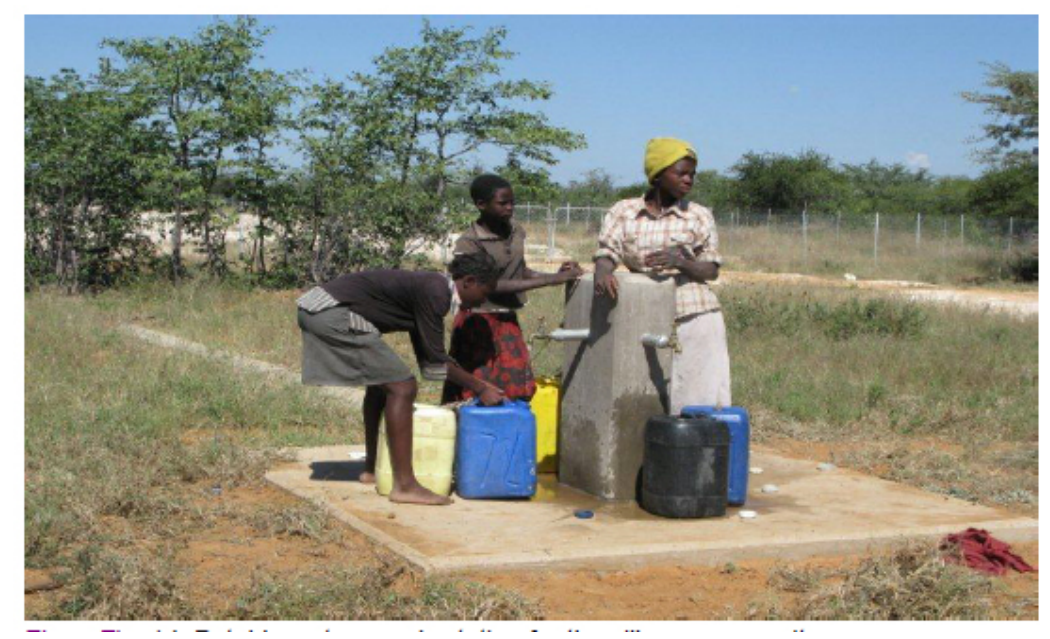

Fig. (14). Potable water supply station for the village community.

\section{CONCLUSION}

Looking for suitable condensing surfaces for desalination plants on the MSD method, experimental investigations were carried out for mass and heat transport in a specially developed bench scale test rig. A total of 6 different condensation surfaces were examined in respect to their thermodynamic, structural, and user-friendly properties. The results of laboratory measurements and the verification with an 8 stage prototype apparatus show that it is useful to describe the heat transfer coefficients (k-values), the theoretical condensation rates, the measured rates of condensation and the condensate yield as a function of the mean temperature value.

An advantage of the representation of this relationship is the possibility of a very simple assessment of the suitability of various condensation surfaces for use in the MSD system, the estimation of rates of condensation, the 
degree of heat recovery for arbitrarily large condensation surfaces and any selected temperature or temperature differences between the evaporator and stage. This allows describing the heat and mass transfer by a simple mathematical relationship for an n-stage MSD system in sufficient detail. As a result of this the drinking water production of the entire system can be estimated. This leads to a considerable simplification compared to the previous practice.

\section{LIST OF ABBREVIATIONS}

\begin{tabular}{|c|c|c|}
\hline $\boldsymbol{A}$ & $=$ & Area $m^{2}$ \\
\hline $\mathbf{A F}$ & $=$ & Metal sheets with an oxidic surface \\
\hline$A_{S t}$ & $=$ & Stage area $\mathrm{m}^{2}$ \\
\hline$A_{\text {Sto }}$ & $=$ & Storage area $\mathrm{m}^{2}$ \\
\hline BF & $=$ & Expanded metal with a hydrophilic foil \\
\hline$c_{p}$ & $=$ & Specific heat $\mathrm{J} \mathrm{kg}^{-1} \mathrm{~K}^{-1}$ \\
\hline GF & $=$ & Glass and temperature resistant foil \\
\hline GOR & $=$ & Gained Output Ratio \\
\hline $\mathbf{k}_{1}$ & $=$ & Overall heat transfer coefficient inside the system $\mathrm{W} \mathrm{m}^{-2} \mathrm{~K}^{-1}$ \\
\hline $\mathbf{k}_{2}$ & $=$ & Overall heat transfer coefficient outside the system $\mathrm{W} \mathrm{m}^{-2} \mathrm{~K}^{-}$ \\
\hline$m$ & $=$ & Mass kg \\
\hline $\boldsymbol{m}_{C o n}$ & $=$ & Condensate mass over all stages $\mathrm{kg}$ \\
\hline $\boldsymbol{m}_{\text {Sto }}$ & $=$ & Water mass in the storage $\mathrm{kg}$ \\
\hline$\dot{m}$ & $=$ & Mass flow rate $\mathrm{kg} \mathrm{s}^{-1}$ \\
\hline $\mathbf{m}_{\text {cal }}$ & $=$ & Calculated condensate mass $\mathrm{kg}$ \\
\hline$\dot{m}_{\text {Con }}$ & $=$ & Mass flow rate over all stages $\mathrm{g} \mathrm{m}^{-2} \mathrm{~h}^{-1}$ \\
\hline$\dot{m}_{s p, \text { Con }}$ & $=$ & Spec. mass flow rate $\mathrm{g} \mathrm{m}^{-2} \mathrm{~h}^{-1}$ \\
\hline$\dot{m}_{t h, s p}$ & $=$ & Theor. spec. mass flow rate $\mathrm{g} \mathrm{m}^{-2} \mathrm{~h}^{-1}$ \\
\hline NF & $=$ & Stainless steel surface with nano-coatings \\
\hline$\dot{Q}_{e l}$ & $=$ & Electr. heat flow W \\
\hline$Q_{\text {in }}$ & $=$ & Heat input $\mathrm{kJ}$ \\
\hline$Q_{s t}$ & $=$ & Heat flow stage $\mathrm{W}$ \\
\hline$\dot{Q}_{\text {Sto }}$ & $=$ & Heat flow storage $\mathrm{W}$ \\
\hline$\dot{R}\left(T_{m}\right)$ & $=$ & Return drip rate $\mathrm{g} \mathrm{m}^{-2} \mathrm{~h}^{-1}$ \\
\hline$r$ & $=$ & Spec. enthalpy of vaporization $\mathrm{J} \mathrm{kg}^{-1} \mathrm{~K}^{-1}$ \\
\hline $\boldsymbol{s}_{W}$ & $=$ & Wall thickness m \\
\hline$T$ & $=$ & Temperature $\mathrm{K} ;{ }^{\circ} \mathrm{C}$ \\
\hline $\mathbf{T}_{\mathrm{Am}}$ & $=$ & Ambient temperature $\mathrm{K} ;{ }^{\circ} \mathrm{C}$ \\
\hline $\mathbf{T}_{\mathrm{m}}$ & $=$ & Mean temperature ${ }^{\circ} \mathrm{C}$ \\
\hline $\mathbf{T}_{\mathrm{m}, \mathrm{low}}$ & $=$ & Lower mean temperature ${ }^{\circ} \mathrm{C}$ \\
\hline $\mathbf{T}_{\mathrm{m}, \mathrm{up}}$ & $=$ & Upper mean temperature ${ }^{\circ} \mathrm{C}$ \\
\hline $\mathbf{T}_{\mathrm{st}}$ & $=$ & Stage temperature ${ }^{\circ} \mathrm{C}$ \\
\hline $\mathbf{T}_{\text {Sto }}$ & $=$ & Storage temperature ${ }^{\circ} \mathrm{C}$ \\
\hline UB & $=$ & Untreated stainless steel \\
\hline UF & $=$ & Expanded metal with temperature resistant foil \\
\hline$\alpha_{1}$ & $=$ & Spec. heat transition coefficient, steam side $\mathrm{W} \mathrm{m}^{-2} \mathrm{~K}^{-1}$ \\
\hline$\alpha_{2}$ & $=$ & Spec. heat transition coefficient, water side $\mathrm{W} \mathrm{m}^{-2} \mathrm{~K}^{-1}$ \\
\hline$\eta_{\text {con }}$ & $=$ & Condensate yield \% \\
\hline$\lambda_{\mathrm{w}}$ & $=$ & Coefficient of thermal conductivity (wall) $\mathrm{W} \mathrm{m}^{-1} \mathrm{~K}^{-1}$ \\
\hline
\end{tabular}




\section{CONFLICT OF INTEREST}

The authors confirm that this article contains no conflict of interest.

\section{ACKNOWLEDGEMENTS}

The authors would like to thank the Ministry of Education and Research (BMBF) for financial support for the project Aquasol (FKZ 02WT0605).

\section{REFERENCES}

[1] UNESCO, "Water and Energy", The United Nations World Water Development Report 2014, UNESCO, 2014. Available at: http://unesdoc.unesco.org/images/0022/002257/225741e.pdf

[2] WHO, "Drinking-Water", Fact sheet No. 391, WHO, 2015. Available at: http://www.who.int/mediacentre/factsheets/fs391/en/

[3] "IDA World Congress: The State of Desalination 2011", Available at: http://desalination.edu.au/2011/09/ idaworldcongress-the-state-ofdesalination-2011

[4] J. Gebel, and S. Yüce, "An Engeineer's Guide to Desalination", VGB Power Tech Service GmbH: Germany, 2008.

[5] M. Papapetrou, and C. Epp, "Autonomous Desalination Units Based on Renewable Energy Systems - A Review of Representative Installations Wordwide", In: Solar Desalination for the 21 $1^{\text {st }}$ Century, Springer Verlag, 2007. ISBN 978-1-4020-5507

[6] L. Rizzuti, and H. M. Ettouney, "A Review of Modern Technologies and Researches on Desalination Coupled to Renewable Energies", In: Solar Desalination for the $21^{\text {st }}$ Century, Springer: Netherlands, 2007.

[7] L. Garcia- Rodríguez, "Renewable energy applications in desalination: state of the art", Sol. Energy, vol. 75, pp. 381-393, 2003. [http://dx.doi.org/10.1016/j.solener.2003.08.005]

[8] K. Schwarzer, E. Vieira da Silva, and B. Hoffschmidt, "A new solar desalination system with heat recovery for decentralised drinking water production", Desalination, vol. 248, no. 3, pp. 204-211 2008.

[9] K. Schwarzer, B. Hoffschmidt, and T. Schwarzer, "Verbundprojekt: Entwicklung Optimierung und Feldtest einer neuartigen solarthermischen Meerwasserentsalzungsanlage mit mehrstufiger Wärmerückgewinnung (AQUASOL)", BMBF.-Schlussbericht, Förderkennzeichen: 02WT0606, Mai, Berlin, 2011.

[10] K. Schwarzer, M.E. Vieira da Silva, T. Schwarzer, and P. Wedding, "Recent results of the field tests with the new solar desalination system for decentralized drinking water production in Namibia and Brasil", EUROMED-Conference, Barcelona: Spain, 2010.

[11] C. Dreiser, and H-J. Bart, "Solvent interactions with polymeric heat transfer surfaces", J. Mater. Sci. Eng., vol. A3, no. 9, pp. 591-600, 2013.

[12] C. Dreiser, L.J. Krätz, and H-J. Bart, "Polymer film heat exchanger for seawater desalination: Prevention and cleaning of fouling deposits", In: H. Müller-Steinhagen, M. R. Malayeri, and A. P. Watkinson, Eds., Proceedings of International Conference on Heat Exchanger Fouling and Cleaning X, 2013, pp. 296-301.

[13] J.B. Christmann, L.J. Krätz, and H-J. Bart, "Falling film evaporation with polymeric heat transfer surfaces", Desalination, vol. 308, pp. 56-62, 2013

[http://dx.doi.org/10.1016/j.desal.2011.05.027]

[14] J.B. Christmann, L.J. Krätz, and H-J. Bart, "Novel polymer film heat exchangers for seawater desalination", Desalination Water Treat., vol. 21, pp. 162-174, 2010. [http://dx.doi.org/10.5004/dwt.2010.1325]

[15] C. Dreiser, and H-J. Bart, "Challenges in design of polymer falling film heat exchangers", Chemical Eng. Transac., vol. 29, pp. 1351-1356, 2012 .

[16] T. Schwarzer, "Thermodynamische, konstruktive und nutzerbezogene Optimierung einer solaren Mehrstufenentsalzungsanlage (MSD), ", PhD Thesis: Universität Kaiserslautern, Shaker Verlag, Aachen, 2013. ISBN 3-8440-2083-0

[17] "Water is life - omeya ogo om wenyo", CuveWater mid-term report, CuveWater integrated water resources management, 2015.

(C) Schwarzer and Bart; Licensee Bentham Open.

This is an open access article licensed under the terms of the Creative Commons Attribution-Non-Commercial 4.0 International Public License (CC BY-NC 4.0) (https://creativecommons.org/licenses/by-nc/4.0/legalcode), which permits unrestricted, non-commercial use, distribution and reproduction in any medium, provided the work is properly cited. 